\title{
Inline High Speed Laser Cutting of Band Material
}

\author{
Andreas Wetzig ${ }^{1}$, a ${ }^{*}$, Jan Hauptmann ${ }^{1}$, Patrick Herwig ${ }^{1}$, Eckhard Beyer ${ }^{1,2}$ \\ Wieland Bundschuh ${ }^{3, b}$, Simon Volk ${ }^{3}$, Mark Hemberger ${ }^{3}$ \\ ${ }^{1}$ Fraunhofer IWS, Winterbergstr. 28, 01277 Dresden, Germany \\ ${ }^{2}$ Technische Universität Dresden, Institut für Fertigungstechnik, 01062 Dresden, Germany \\ ${ }^{3}$ Scheuermann + Heilig GmbH, 74722 Buchen-Hainstadt, Germany \\ aandreas.wetzig@iws.fraunhofer.de, ${ }^{b}$ wieland.bundschuh@sh-gmbh.de
}

\section{Keywords: Laser High Speed Cutting, Remote Laser Cutting, Band Material}

\begin{abstract}
Laser cutting is introduced as an alternative technique to manufacture typical metallic punching and bending parts. Assets and drawbacks of high speed laser cutting technologies like Remote Laser Cutting and laser fusion cutting by means of a high dynamic form cutter are discussed. Finally, the concept of the world's first industrial inline reel to reel laser cutting machine for metal strips is presented.
\end{abstract}

\section{Introduction}

The usage of high precision metallic punching and bending parts is wide-spread among the industry, for example these components are utilized frequently as a cost efficient solution within the automotive, medical, electronic, and consumer goods industry, to name only a few.

The state of the art technology to cut these parts within a high volume production is a progressive punching process using metal strips from coils as semi-finished materials. Punching is a well-engineered and mature technology which provides acceptable cutting results for metallic parts in terms of flatness, surface quality, and contour precision in combination with low production costs. The limiting factor for the well-established punching process is the lack of flexibility due to the tool bounding, e.g. changes of an existing part design cannot be done easily. This leads to an early design freeze during the development process, which leads to high costs for design variants and modifications, and thus the time to market is too long for current industry requirements. In addition, there is a general trend to apply steel grades with higher material strength which may lead to tool failure causing high costs due to unintended stops in production. Last but not least, punching technology is associated with certain design limits which means that intricate contours are difficult to achieve. Finally, an alternative/supplementary cutting technology needs to be investigated that is suitable for high volume production while not increasing the product costs for the customers [1].

Conventional laser fusion cutting seems to be a good option because it addresses all of the flexibility issues whereas the cutting quality is still within an acceptable range. Laser technology has not been applied thus far because the cycle time needed to laser cut a part is typically one order of magnitude higher than the required cycle time of less than one second for a cost effective inline cutting and forming process. Even if the potential is given by the available laser power and beam quality, the bottle neck is the motion system used on filigree contours movement.

There are two different opportunities to cut faster: On one hand, the so called Remote Laser Cutting which uses fast galvo driven mirrors to manipulate the laser beam while the cutting is done without an assisting gas. On the other hand, the High Dynamic Form Cutter (HFDC) enables high cutting speeds by means of integrated fast linear axes while still using gas to eject the molten material.

\section{Remote Laser Cutting}

Remote Laser Cutting as a novel high speed progressive cutting process has been developed to overcome this drawback of conventional cutting by increasing the mean cutting speed by a factor of 
10. Using a fiber laser with single mode beam quality allows cutting or rather ablation without a cutting gas by providing the required power density at the focal point. The process is characterized by a cyclic ablation of the cut kerf material as shown in Fig. 1. The process uses a mix of molten and vaporized material in the process area. The vaporization is needed to eject the molten material out of the cut kerf whereas the portion of vaporized metal in the case of steel fluctuates between 25 and 50 percent [2]. The single ablation depth depends on material, laser power, laser intensity, feed rate, and existing groove [3]. The black circles of Fig. 2 show the laser power which is needed in combination with a certain feed rate to achieve an ablation depth of about 30 to $50 \mu \mathrm{m}$ for stainless steel. Consequently, a minimum laser power of $500 \mathrm{~W}$ is required as well as a minimum speed of $350 \mathrm{~m} / \mathrm{min}$ to maintain an ablation cutting process with laser power intensities within a magnitude of $10^{8} \mathrm{~W} / \mathrm{cm}^{2}$.

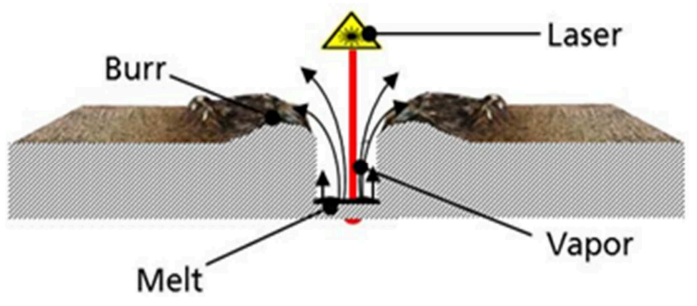

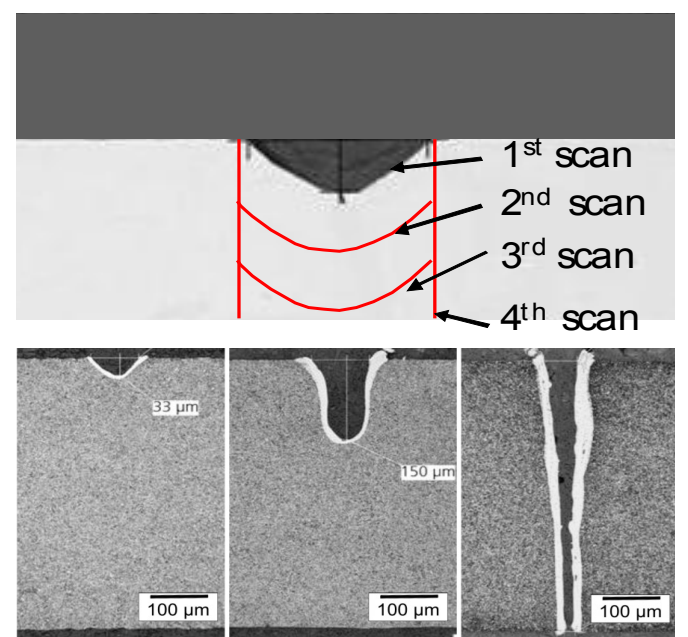

Fig. 1: Cyclic ablation of remote cutting process

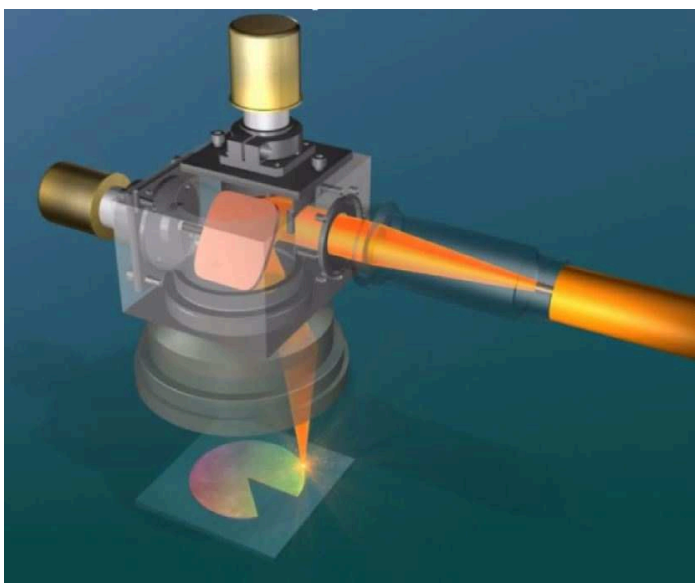

Fig. 3: Schematic of beam manipulation by galvanometer driven mirrors

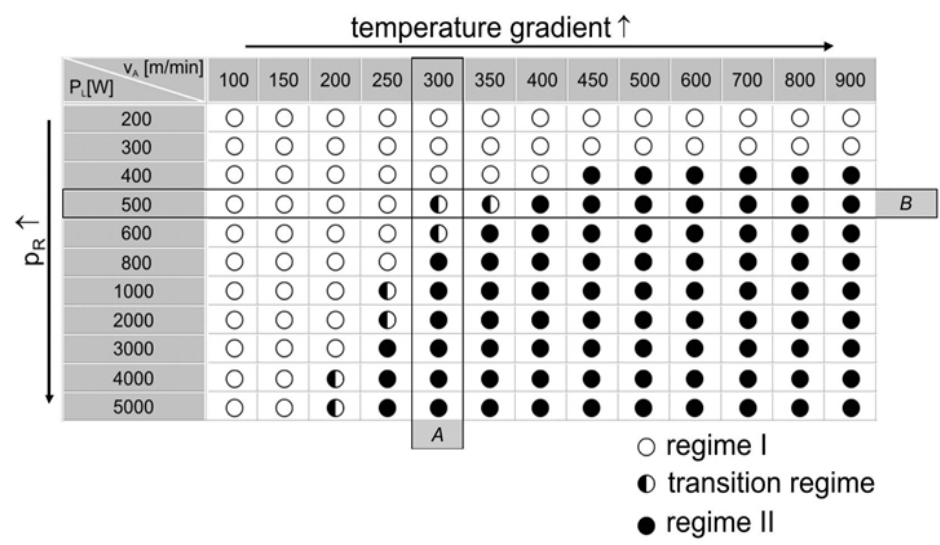

Fig. 2: Ablation process (regime II) depending on laser power and speed

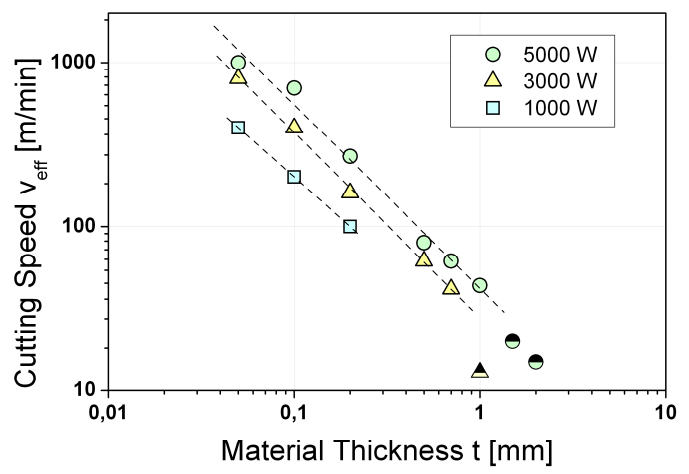

Fig. 4: Effective cutting speed depending on laser power and thickness for steel (1.4301) 
A conventional laser cutting head as well as Cartesian axes which is used for the relative motion between laser and work piece is not needed any more. In fact, fast galvanometer axes are taking over the movement of the laser beam resulting into path speeds on the work piece of up to $1000 \mathrm{~m} / \mathrm{min}$ (Fig. 3). Depending on the material thickness several laser passages are necessary. As a result, material thicknesses from 0.05 up to $0.5 \mathrm{~mm}$ for many metal materials used in industry can be remote cut by means of single mode fiber laser with final velocities between 50 and $1000 \mathrm{~m} / \mathrm{min}$. Fig. 4 shows the resulting cutting speed for different laser power and identical focus size for a single path speed of $1000 \mathrm{~m} / \mathrm{min}$ as a function of the material thickness for cutting of stainless steel (1.4301) [4].

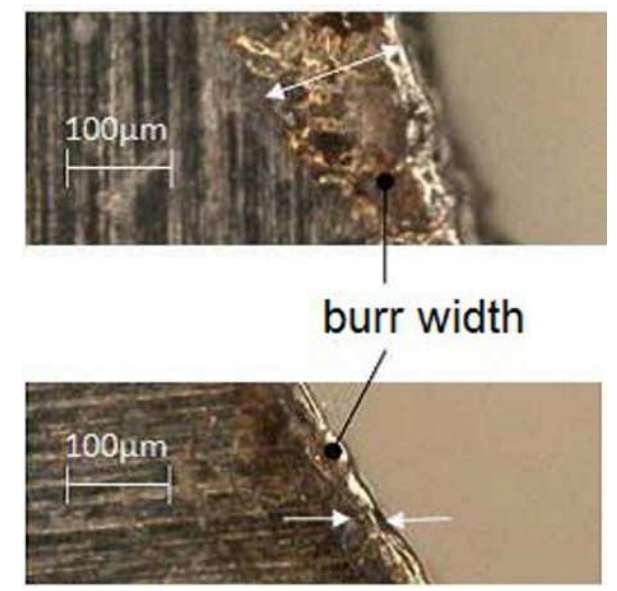

Fig. 5: Formation of burr before (top) and after process optimization (bottom)

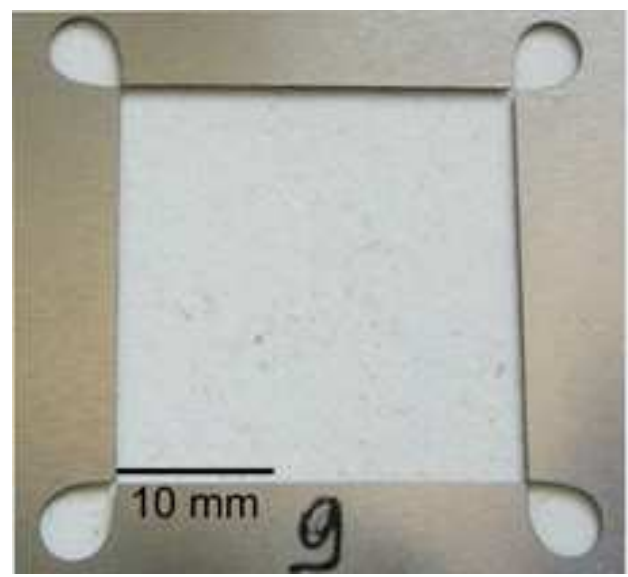

Fig. 6: Remote cutting of sharp edges by means of so called sky writing

On the other hand, there are several drawbacks compared to conventional fusion cutting. Firstly, the burr occurs on the top side of the sheet instead of the bottom side. The height of the burr is in the range of one tenth of the sheet thickness and it can be reduced after process optimization as shown in Fig. 5. An example of process optimization would be to keep the focal point on the ideal z-position and to adapt the cutting parameters like laser power and speed according to the depth of the groove (Fig. 1). Secondly, the extremely high velocity of a single laser path may cause contour deviations that can be reduced both by smart cutting strategies and by anticipating path planning (Fig. 6). Also, the working field is limited to $100 \mathrm{~mm}$ by $100 \mathrm{~mm}$ which is still sufficient for the majority of typical metallic punching and bending parts [5].

\section{High Dynamic Form Cutter (HDFC)}

In the case of a thicker material of more than $0.5 \mathrm{~mm}$ and/or highest standards for contour accuracy and total burr less edge quality another innovation is utilized for manufacturing punching and bending parts: the High Dynamic Form Cutter (HDFC) which was developed to close the gap between conventional fusion cutting and remote cutting. The cutting process still uses a gas to eject the molten material, but the moving masses are dramatically reduced to less than $2 \mathrm{~kg}$ and driven by integrated fast linear axes (Fig. 7). The working envelope is $60 \mathrm{~mm}$ by $60 \mathrm{~mm}$ in the $\mathrm{x}$ and $\mathrm{y}$ direction with a maximum acceleration of $3 \mathrm{~g}$ respectively and $20 \mathrm{~mm}$ stroke in $\mathrm{z}$ direction [6]. 


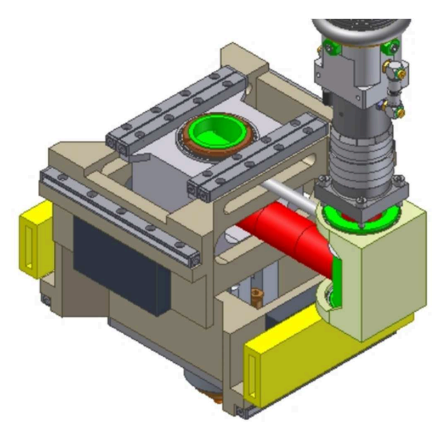

Fig. 7a: Schematic of HDFC

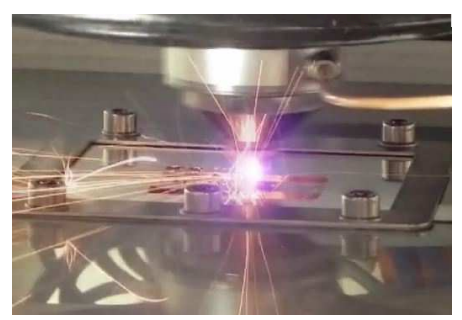

Fig. 7b: Fusion cutting by means of HDFC

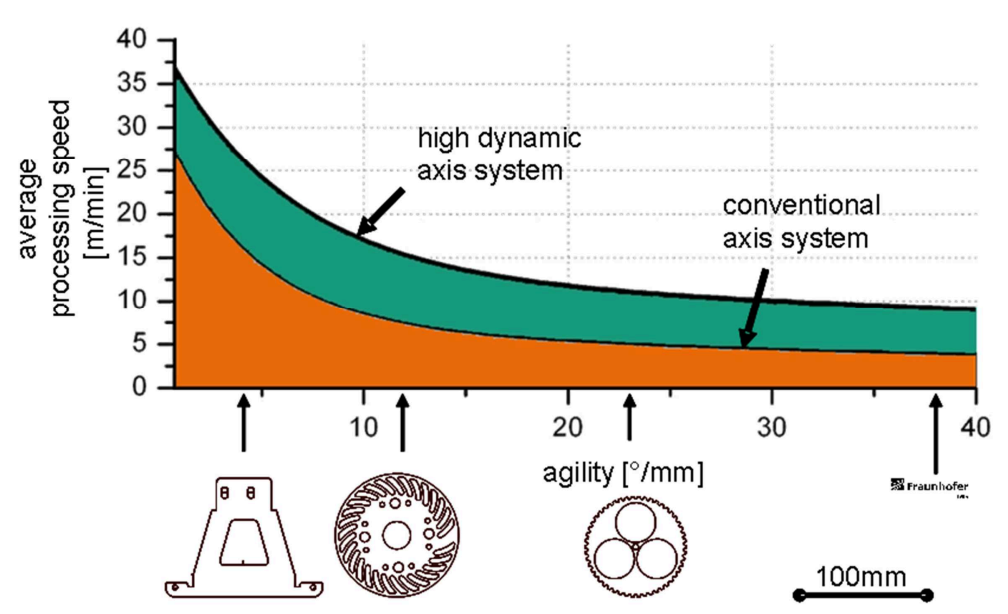

Fig. 8: Average processing speed depending on the contour fineness

Thus, the average cutting speed is up to three times higher compared to a conventional machine based on Cartesian axes. The increase depends on the so called agility (Fig. 8) which is a degree of fineness of a certain contour. Agilities between 10 and $30 \% \mathrm{~mm}$ can be assumed for typical metallic punching and bending parts. Subsequently, the usage of the HDFC enables average cutting speeds of more than $10 \mathrm{~m} / \mathrm{min}$ compared to $5 \mathrm{~m} / \mathrm{min}$ that can be achieved by means of conventional axes [7].

Furthermore, cycle times are achieved that are not as low as by means of remote cutting but which are low enough to justify the use of laser technology to cut parts economically that can neither be remote cut nor be punched. Consequently, the cycle times of HDFC when compared with remote cutting are higher. However, the cycle times of HDFC are economically justifiable for parts that cannot be remote cut or mechanically punched.

\section{Industrial Implementation of Inline High Speed Laser Cutting of Band Material}

In 2010, SCHEUERMANN + HEILIG GmbH as one of the leading European manufacturers of small highly precise punching-bending parts, springs and subassemblies became aware of the progress in Remote Laser Cutting Technology for metals reached at the Fraunhofer IWS Dresden. A bilateral research project was started to check the applicability, the benefits, and the limitations of this new technology for their products and customers. The project was partially financed by the German Government within the ZIM program for SME. It could be shown that the cutting quality and precision achieved by means of Remote Laser Cutting is sufficient for many typical applications of punching-bending parts (according to DIN 6930-f e.g.). In addition, the geometrical feasibility limits and the productivity are significantly enlarged compared to alternative state of the art technologies like laser fusion cutting or etching.

Due to these encouraging results, it was decided to develop and built up the world's first industrial inline reel to reel laser cutting machine for metal strips based on Remote Laser Cutting technology. In addition to the remote scanner optics a High Dynamic Form Cutter (HDFC) system was integrated in the machine in order to enable a sheet metal strip cutting of thicknesses up to $1 \mathrm{~mm}$. Thus, the single mode fiber laser can be used either for Remote Laser Cutting of sheet metal strips up to $0.5 \mathrm{~mm}$ or for Laser Fusion Cutting of strips up to $1 \mathrm{~mm}$ thickness by using the HDFC cutting technology. The machine is suitable for reel to reel cutting processes as well as for inline cutting-forming processes in cooperation with conventional forming machines. 


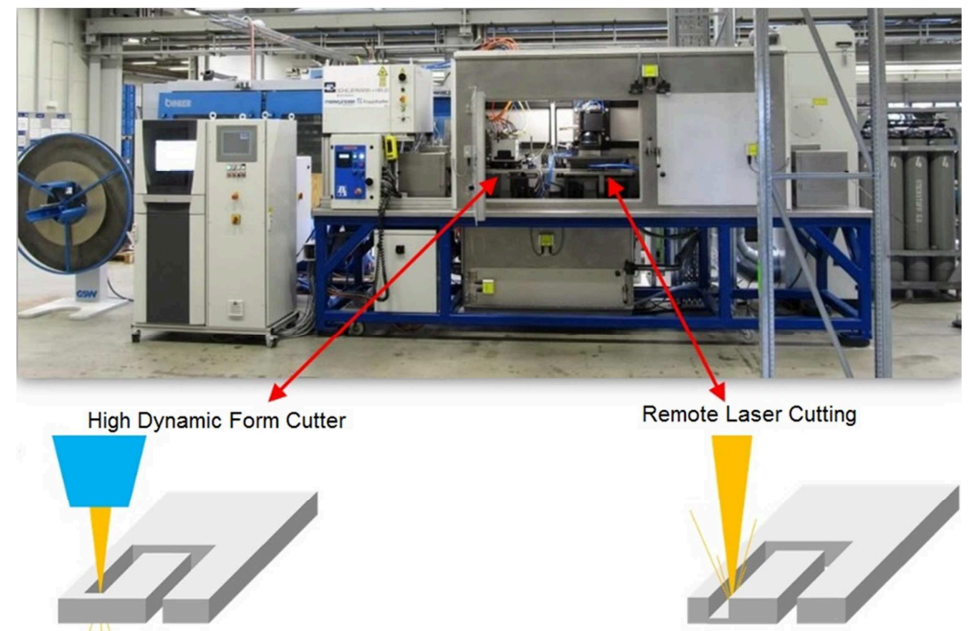

Fig. 9: View of the inline reel to reel laser cutting machine for metal strips

Series operation of the new cutting machine started in October 2013. Fig. 9 shows the general layout of the machine. It is equipped with hasp systems for the sheet metal strip handling, strip feeding systems, strip clamping and positioning systems, an HDFC cutting head, a remote cutting head, an optional strip cleaning system, an optical quality control system, and a multi $\mathrm{kW}$ single mode fiber laser. The first high volume series laser cutting application by means of an HDFC is shown in Fig. 10. Up to now, more than half a million of these parts were produced without any quality or degradation problems. The machine concept as well as the HDFC cutting system has been proven to be very reliable.

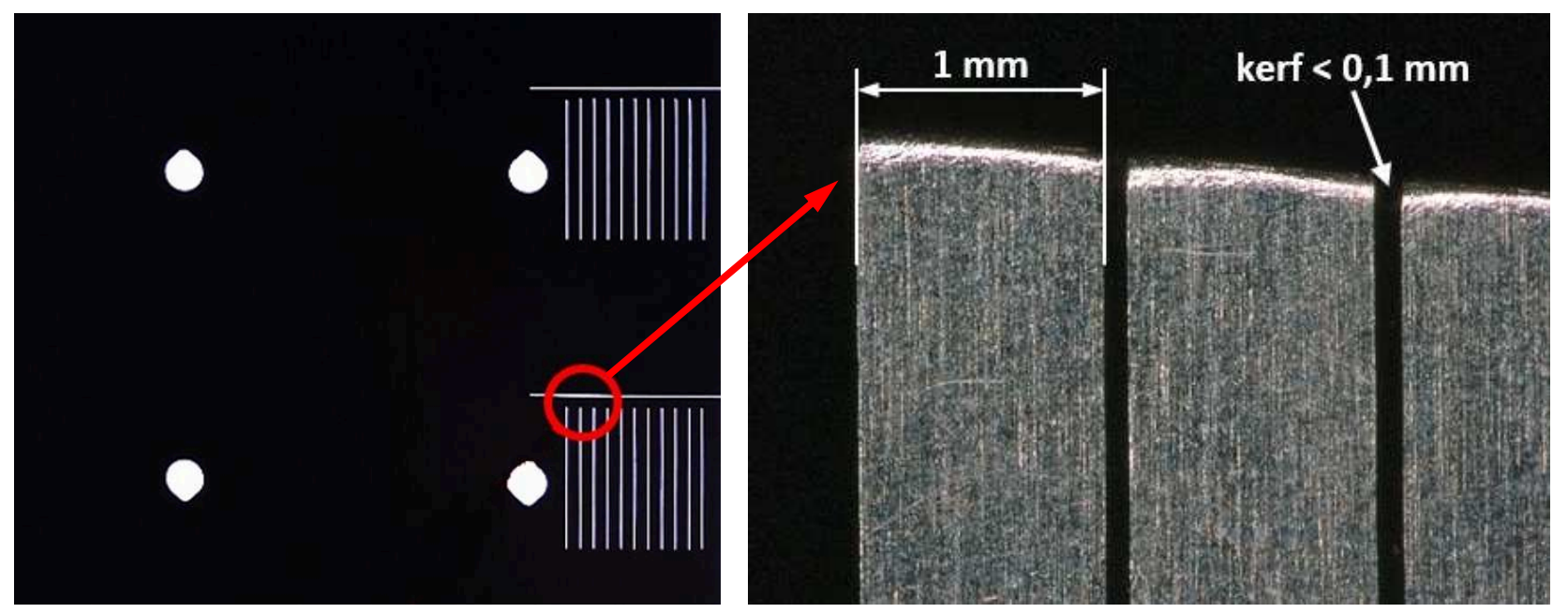

Fig. 10: First high volume series laser fusion cutting application using the HDFC

Fig. 11 comprises pictures of various prototypes of Laser Remote cut parts. Fig. 11a shows a copper part with about 150 narrow $(<100 \mu \mathrm{m})$ cutting kerfs. Laser fusion cutting is not applicable for this part because the high pressure gas jet which is associated with fusion cutting would damage the filigree shape. Fig. $11 \mathrm{~b}$ visualizes the possibility to produce narrow hole patterns for filters e.g. by Laser Remote Cutting or rather Laser Remote Drilling. Fig. 11c shows a sheet metal blank for a stainless membrane spring application. Due to the short cutting time of less than $250 \mathrm{~ms}$ Laser Remote Cutting is for this application much more economic compared to conventional Laser Fusion Cutting or etching. Punching is impossible due to a very high risk of tool failure. 
However, surface quality of Remote Laser cut blanks is still lower compared to etching e.g. and in some cases it is the exclusion criterion. Especially the formation of cutting burr (see Fig. 5) due to the ejected molten material it is not accepted for certain applications (for medical purposes e.g.). Therefore, future development work on Laser Remote Cutting will further put the focus on concepts to improve the surface quality.
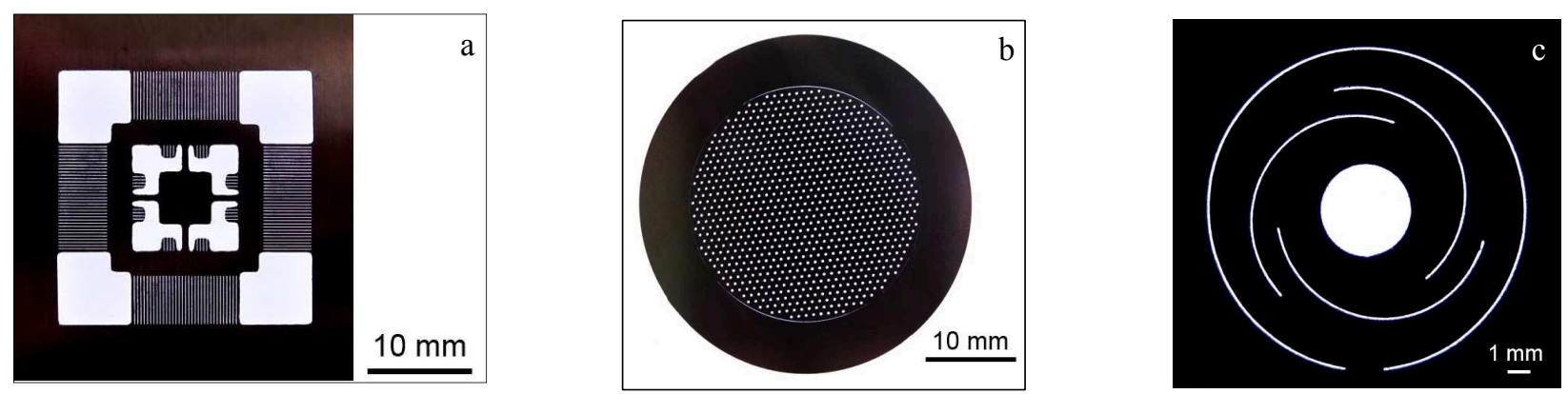

Fig. 11: Applications examples of Remote Laser cut parts

\section{Summary}

Remote Laser Cutting as well as high speed laser fusion cutting by means of a High Dynamic Form Cutter (HFDC) is proven alternative techniques to cut high precision metallic punching and bending parts. Which one of the possible cutting techniques like Remote Laser Cutting, laser fusion cutting, etching, or punching is chosen depends not only on the cycle time but rather on the general producibility, on the risk of tool failure, on the batch size, on the part precision, and on the specified cutting quality.

\section{References}

[1] W. Bundschuh, S. Volk, A. Wetzig, M. Lütke, Anwendungspotenzial des Hochgeschwindigkeits-Laser-Remote-Schneidens in der Großserienfertigung von StanzBiegeteilen, Tagungsband T36, EFB-Kolloquium Blechbearbeitung Fellbach, 16.- 17.04.2013, EFB, Hannover 2013, Seiten 75-86

[2] A. Mahrle, M. Lütke, E. Beyer, Fibre laser cutting: beam absorption characteristics and gasfree remote cutting, Journal of Mechanical Engineering Science, 2010 Vol 224 No C5, p. 1007-19

[3] M. Lütke, Entwicklung des Remote-Laserstrahlschneidens metallischer Werkstoffe, Fraunhofer IWS, Dresden 2011, Fraunhofer Verlag, ISBN 978-3-8396-0359-8, Dissertation

[4] J. Musiol, M. Lütke, M. Schweier, J. Hatwig, A. Wetzig, E. Beyer, M.F. Zaeh, Combining remote ablation cutting and remote welding: opportunities and application areas, Photonics West, High-Power Laser Materials Processing: Lasers, Beam Delivery, Diagnostics and Applications, 24. - 26.01.2012, San Francisco, California, USA, Vol. 82398239 0Q

[5] A. Wetzig, R. Baumann, P. Herwig, R. Siebert, E. Beyer, Laser Remote Cutting of Metallic Materials: Opportunities and Limitations, Industrial Laser Applications Symposium, ILAS 2015 : 17 - 18 March 2015, Kenilworth, United Kingdom Bellingham, WA: SPIE, 2015 (Proceedings of SPIE 9657), ISBN: 978-1-62841-870-5Paper 965708, 5 pp.

[6] A. Wetzig, Pushing the Solid-State Laser Speed Limit, The Fabricator 45(2015) 1, page 56-58

[7] F. Bartels, B. Suess, A. Wagner, J. Hauptmann, A. Wetzig, E. Beyer, Agility-Complexity Description in a new Dimension Applied for Laser Cutting, Sixth International WLT Conference on Lasers in Manufacturing. Proceedings: May 23-26, 2011, München; LiM 2011, Amsterdam: Elsevier, 2011 (Physics Procedia 12.2011, Pt.1) ISSN: 1875-3892, pp. 543-547 